\title{
ACCESS TO REPRODUCTIVE HEALTH SERVICES AMONG MIGRANT INDONESIAN FEMALE WORKERS IN PENINSULAR MALAYSIA
}

\author{
Pinta Pudiyanti Siregar ${ }^{1}$ and Rosnah Sutan*1 \\ 56000 Cheras, Kuala Lumpur, Malaysia \\ Corresponding author*: Rosnah Sutan \\ Email: rosnah_sutan@yahoo.com OR rosnah.sutan@ppukm.ukm.edu.my
}

${ }^{1}$ Department of Community Health, Faculty of Medicine, National Universiti Malaysia (UKMMC), Jalan Yaakob Latiff,

\begin{abstract}
This study aims to measure the prevalence of reproductive health services accessibility based on the perception of Indonesian migrant female workers in Malaysia and its influencing factors. A cross-sectional study was conducted among the 593 respondents using a semi-guided questionnaire. Participation for this study came from Kuala Lumpur (230 respondents), Johor Bahru (181 respondents) and Penang (182 respondents). The mean age was 26.8 (SD 6.7) years. Their origin area in Indonesia was from Central Java, North Sumatra, and East Java. The prevalence of easy access to reproductive health services was $66.9 \%$. Multiple logistic regression analysis showed that marital status (aOR=0.389, $95 \% \mathrm{Cl}: 0.201, p=0.751)$, good reproductive health knowledge $(a O R=1.123,95 \% \mathrm{Cl}: 1.071,1.177)$, depression $(a O R=0.934$, $95 \% \mathrm{Cl}: 0.884, p=0.986$ ) were the predictors for the good perceptions of reproductive health services accessibility in Peninsular Malaysia. This study depicted that two-third of Indonesian migrant women have an excellent perception of reproductive health services access in Malaysia. Obstacles identified for poor access to the facility were related to time, immigration permit status, and awareness of the assistance needed. Strategies to enhance the accessibility of reproductive health services require collaboration from Indonesian government representatives and non-governmental organisations in Malaysia to help advocate reproductive health services for all, including the Indonesian women workers.
\end{abstract}

Keyword: accessibility perception; migrant; reproductive healthcare

\section{INTRODUCTION}

Health is an individual right, including the migrant. Improving the health welfare of migrant requires a variety of dimensions ${ }^{1,2}$. Sending migrant workers abroad is one method to impact Indonesia's internal economy and politics positively ${ }^{3}$. This positive contribution is based on income generated were sent to their home family in Indonesia ${ }^{4}$. However, the female migrant workers were reported to be victimised in exploitation and have an unclear channel for them to voice their complaints and rights ${ }^{5,6}$. Some may expose to health risks, including the risk of exposure to HIV and AIDS ${ }^{7}$. They have difficulties obtaining information and health advice as heavy work burden that limit their time to access services needed ${ }^{8}$. No matter local people or migrant workers, women's right should have good access to health care, including reproductive health?.

Usage of reproductive health services depended closely on the women perceived needs. Variation in the prevalence will depend on many factors. The majority of modern contraception user was reported higher among the migrate women ${ }^{10}$. A study in Malaysia found that some laws and policies negatively impact migrants, including migrants' rights to get married and have children. Indirectly, it tends to cause migrants to be exposed to trafficking, sexual abuse, and difficulty accessing healthcare needs ${ }^{11}$. Migrant women who have no immigration permits or identification are less likely to access reproductive health services than women who are not migrants ${ }^{12,13}$. Migrant women are likely to become prey, either because they have been conceptualised as prey or because of circumstances ${ }^{14}$. Lacking media coverage on migrant workers being exposed to abuse could be contributing factors for poor advocacy ${ }^{15}$. Female migrant workers are at risk for social ill-related health problems, and many of them have obstacles in achieving basic reproductive health care $^{16-18}$.

Primary healthcare accessibility and quality of services have emphasised the importance of adequacy, accessibility, affordability, appropriateness, and availability ${ }^{19}$. An earlier study in Thailand found that only $14 \%$ of migrant workers accessed health services ${ }^{20}$. Most evidence found in the Asia Pacific region related to poor access to healthcare. Therefore, understanding the barrier in access is needed to protect their people rights. Public health is a responsibility in empowerment to maintain health and strategies to overcome access and quality ${ }^{21}$. Migrant workers per country ranged from $5 \%$ to $60 \%$ depending on the efficiency of the registration system and focused on immigration permit ${ }^{22}$. All immigrants who enter a country for work must have a working permit with medical health assessment done by an 
appointed agency. In Malaysia, the foreign worker's medical examination online registration portal (FOMEMA) has been integrated with the immigration department system for better documentation. However, there is limited data on health monitoring once they are already in the country except for renewing their working permit and visa. It is time to have good data on migrant workers who reside in a recipient country. The health-related matter diseases cover physical, social, and mental health aspects that female migrant workers get little priority ${ }^{23}$. Factors that determine access to healthcare services among female migrant workers need to be assessed. The present study is aimed to measure the female Indonesian workers in Malaysia on their perception and usage of reproductive health services.

\section{METHODOLOGY}

The study was conducted at the Republic of Indonesia Embassy (KBRI) in Kuala Lumpur and the Consulate General of the Republic of Indonesia (KJRI) in Johor Bahru and Penang. Approval for conducting this study was approved by the University Kebangsaan Malaysia Research and Ethics Committee for human study with code given FF-2017-287. The time taken to complete three study sites was between June 2017 and May 2018. All information obtained from the respondents who consented were kept confidential. Each information obtained was anonymous and analysed as collective aggregated data.

Permission from KBRI Kuala Lumpur, KJRI Johor Bahru and KJRI Penang was granted for using their centres to meet with respondents and data collection. Advertisements about the study were posted to these three centres, and recruitment was done based on voluntary participation. Respondents were given verbal and written explanations on the purpose of the study. They can withdraw from the study at any time after recruitment. The inclusion criteria were women of reproductive age (19-45 years old), who had a valid working permit, and lived in Malaysia for a minimum of 12 months.

The reproductive healthcare access perception was defined in the present study as the respondents' views on their experiences accessing reproductive health services while in Malaysia. The items were asked for healthcare access: ease of health service facilities, the rate of payment, communication with doctors, the ease of permission from the employer, the respondent's belief in reproductive health services, and others. The scoring for the accessibility to reproductive healthcare question was based on the Likert scale, and later it was regrouped into a binary category for comparison. Likert scale of 3 and 4 were given score one while the Likert scale 1 and 2 were given score 0 . The total scores were range from 0 to 24 . The cut-off point was 15.49, and below this line is defined as lacking access, and 15.50 and above is defined as easy access to reproductive health services. The validation test for the reproductive health services accessibility perceptions questionnaire shown good internal consistency with Cronbach's alpha 0.849 .

The questionnaire measured sexual and reproductive health information such as the reproductive organs, menstrual cycle, vaginal discharge, family planning methods, sexually transmitted illness, and treatment obtained. Selfhealth rated scale was based on four categories as very healthy, healthy, not healthy and not very not healthy. The Depression Anxiety Stress Scale (DASS 21) in the Indonesian language with Cronbach alpha 0.95 were used with permission granted. Respondents' knowledge and practice about Islam is assessed using a validated questionnaire with Cronbach alpha 0.7. Data were analysed using the Statistical Package for Social Sciences (IBM Statistics SPSS 26.0). Data cleaning were conducted to detect any missing data, error coding or any data value that was not common. After determining the normality analysis of continuous variables, the test continued with descriptive and multiple logistic regression analyses.

\section{RESULT}

Five hundred ninety-three respondents aged 19 to 45 participated in this study with a $96 \%$ response rate, and the mean age was 26.8 (SD 6.7) years. There were 230 respondents from the Kuala Lumpur Federal Territory, 181 respondents from the KJRI Johor Bahru and 182 respondents from the KJRI Penang. The average period of stay in Malaysia was 4.1 (SD 3.17) years. Most of them were aged less than 30 years (76.2\%), Muslims (95.1\%), lived in dormitories $(80.1 \%)$, had high school education level (79.9\%) and unmarried $(89.0 \%)$. Many of the respondents were origin from various parts of Indonesia, and the most were from Central Java (30.2\%), followed by North Sumatra (26.1\%) and East (17.2\%), as illustrated in Table 1. 
Table 1: Socioeconomic distribution of respondents

\begin{tabular}{|c|c|c|c|c|}
\hline Socioeconomic factor & $\begin{array}{l}\text { Total } \\
n=593 \\
(100 \%)\end{array}$ & $\begin{array}{l}\text { Kuala Lumpur } \\
n=230(38.8 \%)\end{array}$ & $\begin{array}{l}\text { Johore Bahru } \\
n=181(30.5 \%)\end{array}$ & $\begin{array}{l}\text { Penang } \\
n=182(30.7 \%)\end{array}$ \\
\hline \multicolumn{5}{|l|}{ Length of stay } \\
\hline$>5$ years & $158(28.8)$ & $78(49.4)$ & $33(20.9)$ & $47(29.7)$ \\
\hline \multicolumn{5}{|l|}{ Living house } \\
\hline Dormitory & $475(80.1)$ & $175(36.8)$ & $155(32.6)$ & $145(30.5)$ \\
\hline Non-Dormitory & 118 (19.9) & $55(46.6)$ & $26(22.0)$ & $37(20.3)$ \\
\hline$\leq 5 \mathrm{~km}$ & $411(69.3)$ & $137(59.6)$ & $109(60.2)$ & $87(47.8)$ \\
\hline$>5 \mathrm{~km}$ & $182(30.7)$ & $93(40.4)$ & $72(39.8)$ & $95(52.2)$ \\
\hline \multicolumn{5}{|l|}{ House-office time } \\
\hline$\leq 18$ minutes & $333(56.2)$ & $166(72.2)$ & $120(66.3)$ & $125(68.7)$ \\
\hline$>18$ minutes & $260(43.8)$ & $64(27.8)$ & $61(33.7)$ & $57(21.3)$ \\
\hline \multicolumn{5}{|l|}{ Age group } \\
\hline$<30$ years & $452(76.2)$ & $172(38.1)$ & $145(32.1)$ & $135(29.9)$ \\
\hline \multicolumn{5}{|l|}{ Education } \\
\hline Juniour high school & $119(20.1)$ & $56(47.1)$ & $26(21.8)$ & $37(31.1)$ \\
\hline $\begin{array}{l}\text { Seniour high school and } \\
\text { above }\end{array}$ & 474 (79.9) & $174(36.7)$ & $155(32.7)$ & $145(30.6)$ \\
\hline \multicolumn{5}{|l|}{ Origin from Indonesia } \\
\hline Central Java & $179(30.2)$ & $72(31.3)$ & $69(38.1)$ & $38(20.9)$ \\
\hline North Sumatra & $155(26.1)$ & $52(22.6)$ & 7 (3.9) & $96(52.7)$ \\
\hline East Java & 102 (17.2) & $43(18.7)$ & $42(23.2)$ & $17(9.3)$ \\
\hline West Java & $62(10.4)$ & $35(15.2)$ & $20(11.0)$ & $7(3.9)$ \\
\hline Others & $95(16.1)$ & $28(12.2)$ & $43(23.8)$ & $24(13.2)$ \\
\hline \multicolumn{5}{|l|}{ Marital status } \\
\hline Single & $429(89.0)$ & $165(38.5)$ & $136(31.7)$ & $128(29.8)$ \\
\hline Married & $164(11.0)$ & $65(39.6)$ & $45(27.4)$ & $54(32.9)$ \\
\hline
\end{tabular}

\section{PERCEPTION ON REPRODUCTIVE HEALTHCARE ACCESS}

There were three sections in the questionnaire about perceptions of reproductive health services access. High perceptions of accessibility to the service for menstrual problems $(73.4 \%)$ compared to vaginal discharge issues $(66.8 \%)$ and family planning $(56.8 \%)$. A total of 386 respondents (65.1\%) stated that clinics with reproductive health services were located near their homes. Second, almost half of the respondents expressed difficulty reporting reproductive health problems to their doctors $(46.5 \%)$ and found it challenging to pay for health insurance (48.1\%). Third, a total of $368(62.1 \%)$ had a perception that their salaries would be reduced if they had reproductive health problems and seek any reproductive healthcare services. The majority satisfied with the quality assessment on the access to reproductive health services in Malaysia (65.3\%).

About $79.6 \%$ of the respondents believed that religious beliefs did not prevent them from accessing reproductive health services. Most respondents felt that confidentiality regarding their problems would be maintained by the doctors $(83.5 \%)$. About $66.0 \%$ of respondents mentioned receiving treatment for reproductive health problems, and $77.9 \%$ felt reluctant to obtain any reproductive health services from male doctors. Most respondents (70.0\%) had a good perception of follow-up visits for regular health screening for reproductive health services. The mean value of perceptions scores of access to reproductive health services was 16.8 (SD 4.7). There were $66.9 \%$ perceived had easy access to reproductive health services. Figure 1 illustrated the findings. 


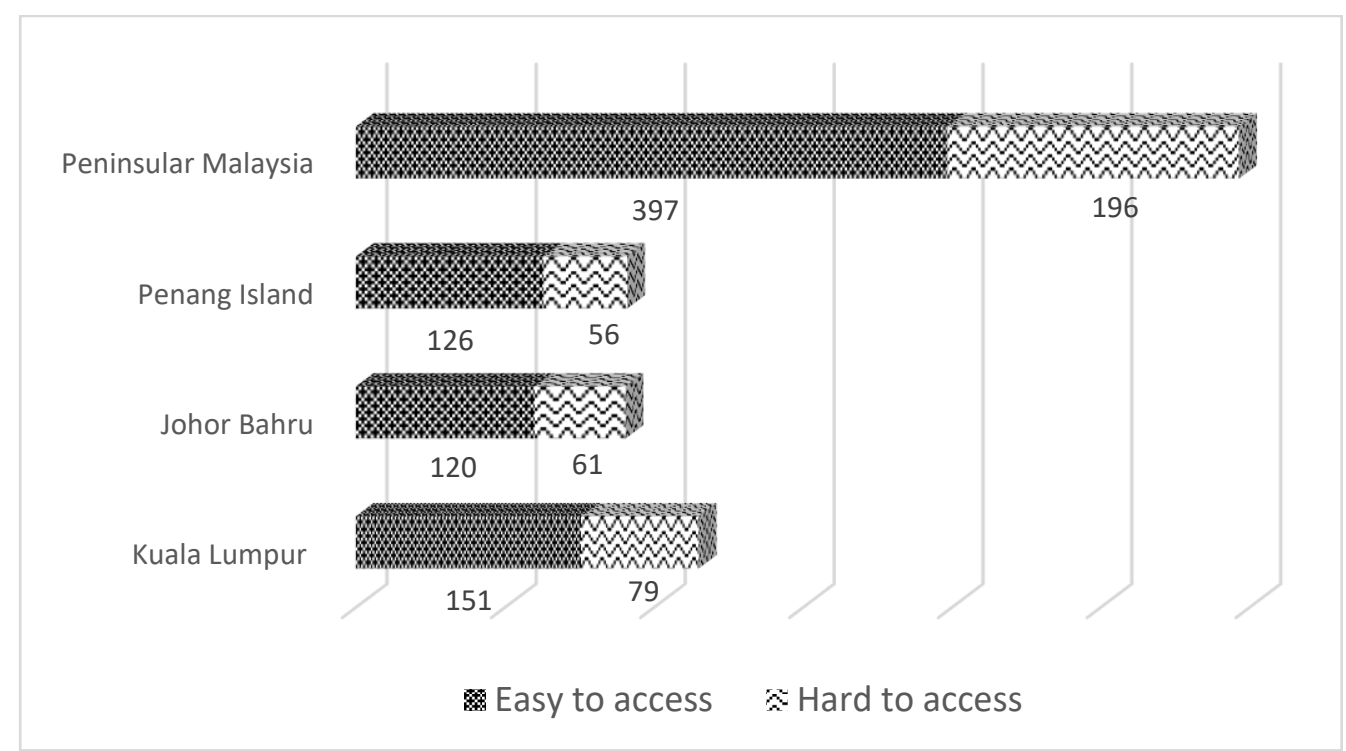

Figure 1. Perception of reproductive healthcare services (n)

\section{Multiple logistic regression analysis}

Tabel 2 showed a multiple logistic regression analysis to determine specific factors that influence reproductive health services accessibility and perception. Health insurance, reproductive health knowledge, self-rated health status, mental health and religiosity were used. Odds ratio (OR) depicted the perception of the reproductive health services scores and noted that it is higher among married workers $\mathrm{OR}=$ 0.389 , 95\% SK: 0.201-0.751; $p=0.005$ ).

The study results also showed that perceptions of efficiently achieving reproductive health services were more likely to be experienced by those who had a high level of reproductive health knowledge $(\mathrm{OR}=1.123,95 \% \mathrm{Cl}: 1.071-1177 ; \mathrm{p}<0.001)$. In addition, the study results also showed that perceptions of hard access the reproductive health services were more likely to be experienced by those with depression ( $\mathrm{OR}=0.934$, 95\% SK: $0.884-0.986 ; p=0.014)$. Thus, the perception of reproductive health access by female migrant workers was influenced by socioeconomic factors, namely marital status, reproductive health knowledge, and depression. Therefore, the total value of Cox \& Snell R square value is 0.129 , and Nagelkerke R square is 0.179 .

Tabel 2: Multiple logistic regression analyses

\begin{tabular}{lllllll}
\hline & Factor & Model & & & & \\
\cline { 3 - 6 } & & Wald & Sig & OR & $\begin{array}{l}\text { Cl 95\% } \\
\text { Lower }\end{array}$ & Upper \\
\hline 1 & & & & & \\
& Socioeconomics & & & & & \\
& Length of stay (years) & 3.752 & 0.053 & 1.089 & 0.999 & 1.188 \\
& Age (years) & 1.940 & 0.164 & 0.966 & 0.919 & 1.014 \\
& Education & 0.184 & 0.668 & 1.166 & 0.578 & 2.354 \\
& Working hours & 0.539 & 0.463 & 0.674 & 0.235 & 1.934 \\
& Length of Working & 0.060 & 0.194 & 0.925 & 0.821 & 1.041 \\
& Working days & 0.939 & 0.332 & 0.899 & 0.726 & 1.115 \\
& Working holidays & 0.000 & 0.992 & 0.997 & 0.513 & 1.935 \\
& Income (RM) & 1.900 & 0.168 & 1.000 & 1.000 & 1.001 \\
& Sending money (RM) & 1.356 & 0.244 & 1.000 & 0.999 & 1.000 \\
& Married status & 7.906 & 0.005 & 0.389 & 0.201 & 0.751 \\
& Living house & 0.027 & 0.869 & 0.913 & 0.310 & 2.693 \\
& Health insurance & 0.337 & 0.562 & 1.155 & 0.710 & 1.880 \\
& Reproductive health & 23.230 & 0.000 & 1.123 & 1.071 & 1.177 \\
& knowledge & & & & & \\
& Self rated health status & 1.916 & 0.166 & 1.564 & 0.830 & 2.947 \\
5 & Mental health & & & & & \\
& Stress & 2.336 & 0.126 & 1.037 & 0.990 & 1.088 \\
& Anxiety & 2.306 & 0.129 & 0.961 & 0.914 & 1.012 \\
& Depression & 5.999 & 0.014 & 0.934 & 0.884 & 0.986 \\
6 & Religiosity & 0.039 & 0.843 & 1.009 & 0.920 & 1.108 \\
\hline
\end{tabular}




\section{DISCUSSION}

The percentage of reproductive health service accessibility perception was $66.9 \%$, of which 397 respondents believed it easy to access reproductive health services. These results showed that more than half of respondents perceive that they have easy access to reproductive health services. This result was a contrary study that found migrant fair to poor to access the healthcare ${ }^{24}$. The factor that was predictor with reproductive health service accessibility perception was marital status. Other studies found that married respondents have a higher percentage who could access reproductive health services than respondents who are not married ${ }^{25,26}$. Understanding married women's lives who already have much experience, especially reproductive health, is challenging. They have gone through the phases of pregnancy and birth, which makes it easier for them to reach the reproductive health service they want. Most respondents with good perceptions of reproductive health services were from those with a high level of reproductive health knowledge. The results of this study are supported by several previous studies, which found that the accessibility of reproductive health services is influence by reproductive health knowledge ${ }^{27-30}$. The barriers to reproductive healthcare services were caused by a lack of knowledge of workers about the benefits.

Mental health problems have a significant predictor with the reproductive health accessibility perception. Respondents who have issues with depression found to have a perception that they have difficulty achieving reproductive health. Studies showed that individuals who have mental health problems also face problems attaining reproductive health services ${ }^{31}$.

Mou (2009) found significant healthcare association access to insurance. Therefore, insurance is a need for these workers, and the same achievement is equivalent to a community that is not migrant ${ }^{32}$, to increase the visibility of health service ${ }^{33}$. The WHO systematic review found that essential factors involving the police and intervention to improve access and quality of health care for migrant workers were immigration status, high socioeconomic status, health insurance, labour union and working conditions ${ }^{34}$. In contrast, we did not found insurance as a predictor of reproductive healthcare accessibility. Nevertheless, advocacy for taking health insurance listed in health policy for migrant workers $^{26}$ has been identified. A previous study suggested the need for multi-dimensional interventions to increase reproductive health services for female migrant workers ${ }^{35,36}$. This study also recommends that there should be migrant-friendly health services at the public health facilities. In addition, Hargreaves, Nellums
\& Friedland (2016) proposed positive contributions involving policies to improve the health of migrants residing in Europe ${ }^{37}$.

The strength of this study is the number of samples taken from three representatives centres of the Indonesian government in Malaysia and all respondents representing each state in Peninsular Malaysia. The limitation of the present study is that it cannot be generalised to Malaysia as we did not cover East Malaysia (Sabah and Sarawak). Focusing on workers' mental health status and its association with SRH practices is noted as a limitation in the present study. It may be possible that workers have had these mental health problems since they were in Indonesia. A cohort study that looks at the extent of changes in the mental health of migrant workers before leaving their hometown while living in donor country and after returning to their homeland is suggested for future study.

\section{CONCLUSION AND RECOMMENDATION}

The results of this study indicate that respondents have a good perception of reproductive health services in Malaysia. However, other factors should be explored, like what the obstacles to the migrant will undoubtedly affect the use of the facility itself. Therefore, future study is recommended to assess the barrier of reproductive health service facilities for Indonesian migrant workers in Malaysia. Furthermore, promoting reproductive health services can be strengthened through collaboration with FOMEMA and the embassy of Indonesia in Malaysia.

\section{ACKNOWLEDGEMENT}

We thanks the UKMREC for approving our study proposal (FF-2017-287). High appreciation to the Embassy of Indonesia in Malaysia for permitting recruitment of respondents at their facilities.

\section{CONFLICT OF INTEREST}

There are no conflicts of interest associated with this publication.

\section{REFERENCES}

1. Agnes C, Donnell O, Burns N, Susanne F, Dowrick C, Clissmann C, et al. Reducing the health care burden for marginalised migrants: The potential role for primary care in Europe. Health Policy (New York) [Internet]. 2016;120(5):495-508. Available from:

http: / /dx.doi.org/10.1016/j.healthpol.201 6.03 .012

2. Brandenberger J, Tylleskär $T$, Sontag $K$, Peterhans B, Ritz N. A systematic literature 
review of reported challenges in health care delivery to migrants and refugees in high-income countries-the $3 \mathrm{C}$ model. $\mathrm{BMC}$ Public Health. 2019;19(1):1-11.

3. Devadason ES, Meng CW. Policies and Laws Regulating Migrant Workers in Malaysia: A Critical Appraisal. J Contemp Asia. 2014;44(1):19-35.

4. Hakim L, Fitrianto A. Political economy of sending domestic workers abroad: Case study of Indonesian migrant workers. Mediterr J Soc Sci. 2015;6(4):316-22.

5. Chan C. Gendered morality and development narratives: The case of female labor migration from Indonesia. Sustain. 2014;6(10):6949-72.

6. Johan Kusuma A, Ryan York M, Hari Wibowo R. Violence against Indonesian Migrant Workers - A Causal Analysis. J Hub Int. 2015;4(1):47-57.

7. Tayah M-J. Global Action Programme on Migrant Domestic Workers and Their Families. 2016;8. Available from: https: //www.ilo.org/wcmsp5/groups/publ ic/---ed_protect/---protrav/-.--

migrant/documents/briefingnote/wcms_53 3536.pdf

8. Organization IL. Women migrant domestic workers in the Arab States: An annotated bibliography. 2015; Available from: http://www.ilo.org/wcmsp5/groups/publi c/---arabstates/---ro-

beirut/documents/projectdocumentation/ wcms_236688.pdf

9. United Nations Human Rights Council. Report of the Special Rapporteur on the right of everyone to the enjoyment of the highest attainable standard of physical and mental health. Promot Prot all Hum rights, civil, Polit Econ Soc Cult rights, Incl right to Dev [Internet]. 2016; A/HRC/32/3(April):127. Available from: https://documentsdds-

ny.un.org/doc/UNDOC/GEN/G16/067/53/P DF/G1606753.pdf?OpenElement

10. Ochako R, Askew I, Okal J, Oucho J, Temmerman M. Modern contraceptive use among migrant and non-migrant women in Kenya. Reprod Health [Internet]. 2016;13(1):1-8. Available from: http: / /dx.doi.org/10.1186/s12978-0160183-3
11. Lasimbang HB, Tong WT, Low WY. Migrant workers in Sabah, East Malaysia: The importance of legislation and policy to uphold equity on sexual and reproductive health and rights. Best Pract Res Clin Obstet Gynaecol [Internet]. 2016;32:113-23. Available from: http://dx.doi.org/10.1016/j.bpobgyn.2015 .08 .015

12. Merold SS. Tracing the Human Right from Law to Policy to Reproductive Healthcare: Exploring the Strengths and Shortcomings of Undocumented Migrant Women's Access to Reproductive Healthcare in Switzerland. 2015;

13. Chekero T, Ross FC. "On paper" and "having papers": Zimbabwean migrant women's experiences in accessing healthcare in Giyani, Limpopo province, South Africa. Anthropol South Africa. 2018;41(1):41-54.

14. Grotti V, Malakasis C, Quagliariello C, Sahraoui N. Shifting vulnerabilities: gender and reproductive care on the migrant trail to Europe. Comp Migr Stud. 2018;6(1).

15. Hamidi M. Indonesian Female Factory Workers: the Gendered Migration Policy in Malaysia. PEOPLE Int J Soc Sci. 2016;2(1):643-64.

16. O'Donnell CA, Burns N, Mair FS, Dowrick C, Clissmann $C$, van den Muijsenbergh $M$, et al. Reducing the health care burden for marginalised migrants: The potential role for primary care in Europe. Health Policy (New York) [Internet]. 2016;120(5):495508. Available from: http://dx.doi.org/10.1016/j.healthpol.201 6.03.012

17. Schmidt NC, Fargnoli V, Epiney M, Irion $O$. Barriers to reproductive health care for migrant women in Geneva: A qualitative study. Reprod Health. 2018;15(1):1-10.

18. Lattof SR, Coast E, Leone T. Priorities and Challenges Accessing Health Care Among Female Migrants. Heal Serv Insights. 2018;11.

19. Forum EP. Defining and Measuring Access to Healthcare: the Patients' Perspective. 2016;(March):1-13.

20. Laohasiriwong W, Khongthanachayopit S. Accessibility to health services among migrant workers in the Northeast of Thailand. F1000Research. 2017;6(0):1-10. 
21. Low WY, Tong WT, Binns C. Migrant workers in Asia pacific and their rights to health. Asia-Pacific J Public Heal. 2015;27(6):5847.

22. Sweileh WM. Global output of research on the health of international migrant workers from 2000 to 201711 Medical and Health Sciences 1117 Public Health and Health Services. Global Health. 2018;14(1):1-12.

23. Ginting $H$, Näring $G$, Van Der Veld WM, Srisayekti W, Becker ES. Validating the Beck Depression Inventory-II in Indonesia's general population and coronary heart disease patients. Int J Clin Heal Psychol. 2013;13(3):235-42.

24. Rozental Y. Access to Health Care among Migrants in Central Asia. 2015;16(6):113848.

25. Chu FY, Chang HT, Shih CL, Jeng CJ, Chen TJ, Lee WC. Factors associated with access of marital migrants and migrant workers to healthcare in Taiwan: A questionnaire survey with quantitative analysis. Int $\mathrm{J}$ Environ Res Public Health. 2019;16(16):111.

26. Sham F, Yaakub S, Fawati FN, Fatinni SJ, Aqiela A, Campus PA, et al. Original Article Knowledge, Attitudes, Risk Behaviours And Preventive Practices On Sexually Transmitted Diseases Among Students In A Public. 2020;20(3):100-8.

27. Loganathan T, Rui D, Ng CW, Pocock NS. Breaking down the barriers: Understanding migrant workers' access to healthcare in Malaysia. PLoS One. 2019;14(7):1-24.

28. Derose KP, Gresenz CR, Ringel JS. Understanding disparities in health care access-

and reducing them-Through a focus on public health. Health Aff. 2011;30(10):1844-

29. Kim LAT, Pham LTL, Vu LH, Schelling E. Health services for reproductive tract infections among female migrant workers in industrial zones in $\mathrm{Ha}$ Noi, Viet Nam: An in- depth assessment. Reprod Health. 2012;9(1):1-11.

30. Zheng Z, Lu C, Lu L. Reproductive Health and Access to Services among Rural-toUrban Migrants in China. 2013; (December):1-29.

31. Lindert J, Ehrenstein OS vo., Priebe S, Mielck A, Brähler E. Depression and anxiety in labor migrants and refugees - A systematic review and meta-analysis. Soc Sci Med. 2009;69(2):246-57.

32. Mou J, Cheng J, Zhang D, Jiang H, Lin L, Griffiths SM. Health care utilisation amongst Shenzhen migrant workers: Does being insured make a difference? BMC Health Serv Res. 2009;9:1-9.

33. Lattof SR, Coast E, Leone T. Priorities and Challenges Accessing Health Care Among Female Migrants. Heal Serv Insights. 2018;11.

34. Simon J, Kiss N, Łaszewska A, Mayer S. Public health aspects of migrant health: a review of the evidence on health status for refugees and asylum seekers in the European Region. WHO Eur. 2015;

35. Mengesha ZB, Perz J, Dune T, Ussher J. Refugee and migrant women's engagement with sexual and reproductive health care in Australia: A socio-ecological analysis of health care professional perspectives. PLoS One. 2017;

36. Smith A, Levoy M. Sexual and Reproductive Health Rights of Undocumented Migrants, European Union. 2016;(February):40. Available from: http: / / picum.org/picum.org/uploads/publ ication/Sexual and Reproductive Health Rights_EN_FINAL.pdf

37. Hargreaves S, Nellums L, Friedland JS. Time to rethink approaches to migrant health screening. Lancet [Internet]. 2016;388(10059):2456-7. Available from: http://dx.doi.org/10.1016/S01406736(16)31703-2 